\title{
Enhanced Video Surveillance (EVS) with Speckle Imaging
}

C. J. Carrano

March 1, 2004

Submitted as an R\&D100 award entry to R\&D Magazine. 
This document was prepared as an account of work sponsored by an agency of the United States Government. Neither the United States Government nor the University of California nor any of their employees, makes any warranty, express or implied, or assumes any legal liability or responsibility for the accuracy, completeness, or usefulness of any information, apparatus, product, or process disclosed, or represents that its use would not infringe privately owned rights. Reference herein to any specific commercial product, process, or service by trade name, trademark, manufacturer, or otherwise, does not necessarily constitute or imply its endorsement, recommendation, or favoring by the United States Government or the University of California. The views and opinions of authors expressed herein do not necessarily state or reflect those of the United States Government or the University of California, and shall not be used for advertising or product endorsement purposes. 


\title{
2004 R\&D 100 Award Entry
}

\section{Enhanced Video Surveillance (EVS) with Speckle Imaging}

\author{
Submitted by \\ Carmen Carrano, James Brase, Doug Poland, Scot Olivier, \\ and Dennis Silva \\ Lawrence Livermore National Laboratory
}

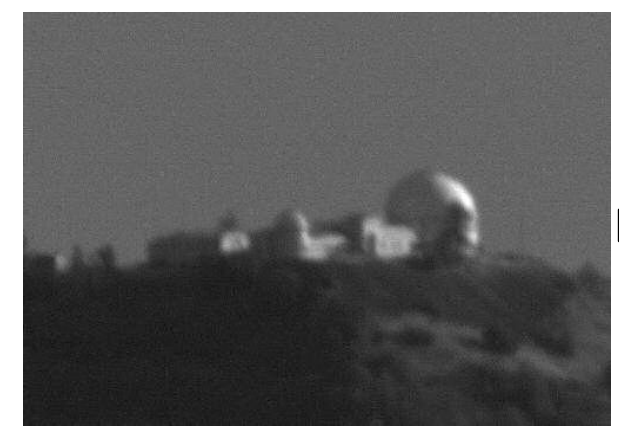

Unprocessed image

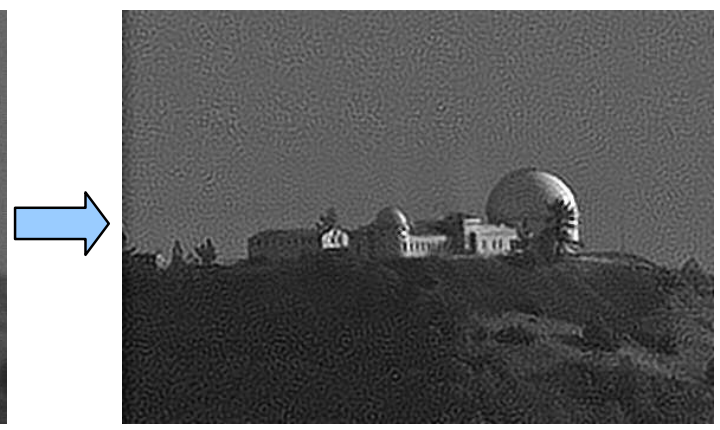

Enhanced Image

Lick observatory imaged from a range of $60 \mathrm{~km}$.

Enhanced Video Surveillance (EVS) with Speckle Imaging provides a clearer view of distant objects using advanced image-processing technology to correct blurring caused by the atmosphere. 
This work was performed under the auspices of the U.S. Department of Energy by University of California, Lawrence Livermore National Laboratory under Contract W-7405Eng-48. 


\section{R\&D 100 AWARDS ENTRY FORM \\ Enhanced Video Surveillance with Speckle Imaging}

$\begin{array}{ll}\text { 1. Submitting Organization: } & \text { Lawrence Livermore National Laboratory } \\ \text { Address: } & 7000 \text { East Avenue, L-290 } \\ \text { City: } & \text { Livermore } \\ \text { State: } & \text { California } \\ \text { Zip Code: } & 94550 \\ \text { Country: } & \text { USA } \\ \text { Submitter's Name: } & \text { Carmen Carrano } \\ \text { Phone: } & (925) 422-9918 \\ \text { Fax: } & (925) 422-8761 \\ \text { Email: } & \text { carrano2@llnl.gov }\end{array}$

AFFIRMATION: I affirm that all information submitted as a part of, or supplemental to, this entry is a fair and accurate representation of this product.

Submitter's signature

\section{Joint entry: Not applicable.}

3. Product name: Enhanced Video Surveillance with Speckle Imaging

\section{Brief description:}

Enhanced Video Surveillance (EVS) with Speckle Imaging is a high-resolution imaging system that substantially improves resolution and contrast in images acquired over long distances. This technology will increase image resolution up to an order of magnitude or greater for video surveillance systems. The system's hardware components are all commercially available and consist of a telescope or large-aperture lens assembly, a high-performance digital camera, and a personal computer. The system's software, developed at LLNL, extends standard speckle-imageprocessing methods (used in the astronomical community) to solve the atmospheric blurring problem associated with imaging over medium to long distances (hundreds of meters to tens of kilometers) through horizontal or slant-path turbulence. This novel imaging technology will not only enhance national security but also will benefit law enforcement, security contractors, and any private or public entity that uses video surveillance to protect their assets.

\section{When was this product first marketed or available for order?}


This high-resolution imaging application was available for licensing beginning in July 2003.

\section{Inventor or Principal Developer}

\begin{tabular}{|c|c|}
\hline Developer Name: & Carmen Carrano \\
\hline Position: & Engineer \\
\hline Organization: & Lawrence Livermore National Laboratory \\
\hline Address: & 7000 East Avenue, L-290 \\
\hline City: & Livermore \\
\hline State: & California \\
\hline Zip/Postal: & 94550 \\
\hline Country: & USA \\
\hline Phone: & (925) 422-9918 \\
\hline Fax: & (925) 422-8761 \\
\hline Email: & carrano2@llnl.gov \\
\hline Developer Name: & James Brase \\
\hline Position: & I-Division Leader \\
\hline Organization: & Lawrence Livermore National Laboratory \\
\hline Address: & 7000 East Avenue, L-290 \\
\hline City: & Livermore \\
\hline State: & California \\
\hline Zip/Postal: & 94550 \\
\hline Country: & USA \\
\hline Phone: & (925) 422-6992 \\
\hline Fax: & (925) 422-8761 \\
\hline Email: & brase1@llnl.gov \\
\hline Developer Name: & Doug Poland \\
\hline Position: & Engineer / Electronics Engineering Group Leader \\
\hline Organization: & Lawrence Livermore National Laboratory \\
\hline Address: & 7000 East Avenue, L-395 \\
\hline City: & Livermore \\
\hline State: & California \\
\hline Zip/Postal: & 94550 \\
\hline Country: & USA \\
\hline Phone: & (925) 422-4980 \\
\hline Fax: & (925) 422-8761 \\
\hline Email: & poland1@\|lnl.gov \\
\hline Developer Name: & Scot Olivier \\
\hline Position: & Adaptive Optics Group Leader \\
\hline Organization: & Lawrence Livermore National Laboratory \\
\hline Address: & 7000 East Avenue, L-290 \\
\hline City: & Livermore \\
\hline State: & California \\
\hline Zip/Postal: & 94550 \\
\hline Country: & USA \\
\hline
\end{tabular}




\begin{tabular}{|c|c|}
\hline $\begin{array}{l}\text { Phone: } \\
\text { Fax: } \\
\text { Email: }\end{array}$ & $\begin{array}{l}\text { (925) 423-6483 } \\
(925) 422-1796 \\
\text { olivier1@llnl.gov }\end{array}$ \\
\hline Developer Name: & Dennis Silva \\
\hline Position: & Tech. Associate \\
\hline $\begin{array}{l}\text { Organization: } \\
\text { Address: }\end{array}$ & $\begin{array}{l}\text { Lawrence Livermore National Laboratory } \\
7000 \text { East Avenue, L-290 }\end{array}$ \\
\hline City: & Livermore \\
\hline State: & California \\
\hline Zip/Postal: & 94550 \\
\hline Country: & USA \\
\hline Phone: & (925) 423-9650 \\
\hline Fax: & (925) 422-8761 \\
\hline Email: & silva8@|lnl.gov \\
\hline
\end{tabular}

\section{Product price}

The price will be established by the licensee(s) and will be determined based on the specifics of the market for which it will be used.

\section{Do you hold any patents or patents pending on this product?}

Yes. The following patent application was filed:

Carmen Carrano and James Brase, "Video Surveillance with Speckle Imaging."

\section{Product Description}

\section{What does it do?}

Enhanced Video Surveillance (EVS) with Speckle Imaging enables high-resolution imaging through atmospheric turbulence, making it possible to identify personnel from hundreds of meters to a few kilometers away and to identify vehicles or monitor sites from tens of kilometers away. When looking through a large-aperture optic (a few inches or more) over long distances, atmospheric blurring degrades the image (Figure 1a). By applying our image-processing technique to multiple short-exposure frames of the scene, it is possible to reconstruct an image of the scene as it would look if there were few or no atmospheric aberrations (Figure 1b). An EVS system can be used to enhance imagery during the daytime or nighttime and at potentially any wavelength of interest (e.g., visible or near-infrared), provided the imaging sensors and optics are configured properly. 


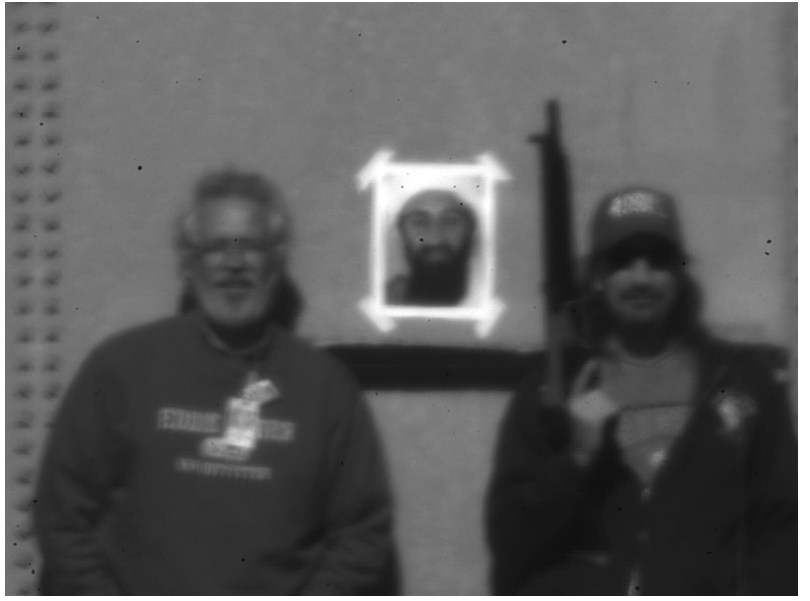

(a) Blurry, unprocessed raw image

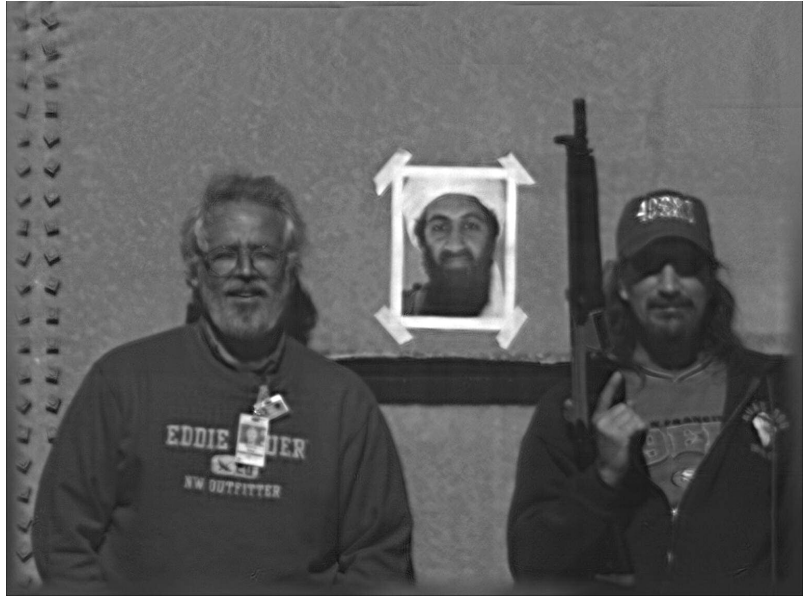

(b) Enhanced image from 40 raw frames

Figure 1. (a) Personnel imaged at a 1-kilometer (0.62 miles) distance through a Celestron 203millimeter (8-inch) aperture telescope with a monochrome charge-coupled device camera using a 5-millisecond exposure time. (b) In the near-photograph-quality processed image, the clothing logos are clearly readable and the faces are identifiable.

\section{How does it do it? What theories, if any, are involved?}

The EVS system incorporates the image-processing technique of speckle imaging, the basis of which was developed in the 1970s and 1980s for astronomical imaging purposes. Speckle imaging has been used successfully for obtaining high-resolution images of events such as the Shoemaker-Levy comet hurtling into Jupiter. ${ }^{1}$ It has also been used for obtaining images of satellites ${ }^{2}$ orbiting the earth. Astronomical imaging usually involves observing a bright, compact object in space, where the atmosphere exists only at a single ground-layer directly above the telescope. EVS with speckle imaging conquers the considerably more complex problem of imaging an extended scene with stronger atmospheric turbulence distributed all along the imaging path. Figure 2 shows the EVS system set up for long distance surveillance over a slant path.

Speckle imaging uses multiple short-exposure frames of the same scene. The short exposures are required to "freeze" the atmospheric aberrations. Typically, exposure times on the order of 10 milliseconds are suitable for this, where the optimal value is determined by both atmospheric and illumination conditions. Freezing the atmosphere preserves high-resolution information in each speckle frame, although the information is somewhat scrambled. Figure 3(a) 
and (b) show the difference between a point source imaged using a long exposure and a short exposure. The speckle-imaging algorithm² ${ }^{2}$ uses the short-exposure frames to estimate both the Fourier magnitude and the Fourier phase of the un-blurred scene and then reconstructs the final image [Figure 3(c)] via an inverse Fourier transform. (See Appendix C for a detailed description of how the algorithm works.) The number of exposure frames needed is typically a few tens to a few hundreds. With a video-rate camera (i.e., one capable of about 30 frames per second), these frames can be acquired using only a second to a few seconds of data-acquisition time.

As stated earlier, modifications to the basic speckle-imaging algorithm were necessary for use with EVS-type imagery. ${ }^{3}$ Because of the non-uniform nature of atmospheric blurring over horizontal and slant paths, it is essential that the large image be split up into smaller images prior to applying the basic speckle-imaging algorithm. These smaller images are then stitched back together. The optimal size of the smaller images depends on how non-uniform the atmosphere is at the time the data is acquired. ${ }^{4}$

The time required to process the imagery depends on many factors, such as the computer hardware, imagery size, and processing parameters. Typical latency times on a standard Pentium IV laptop running at 2.5 gigahertz will range from about a second on small images $(256 \times 256$ pixels $)$ to about a minute on larger images $(1024 \times 1024$ pixels $)$. With multiple CPU's, the minute wait can be reduced to less than 30 seconds.

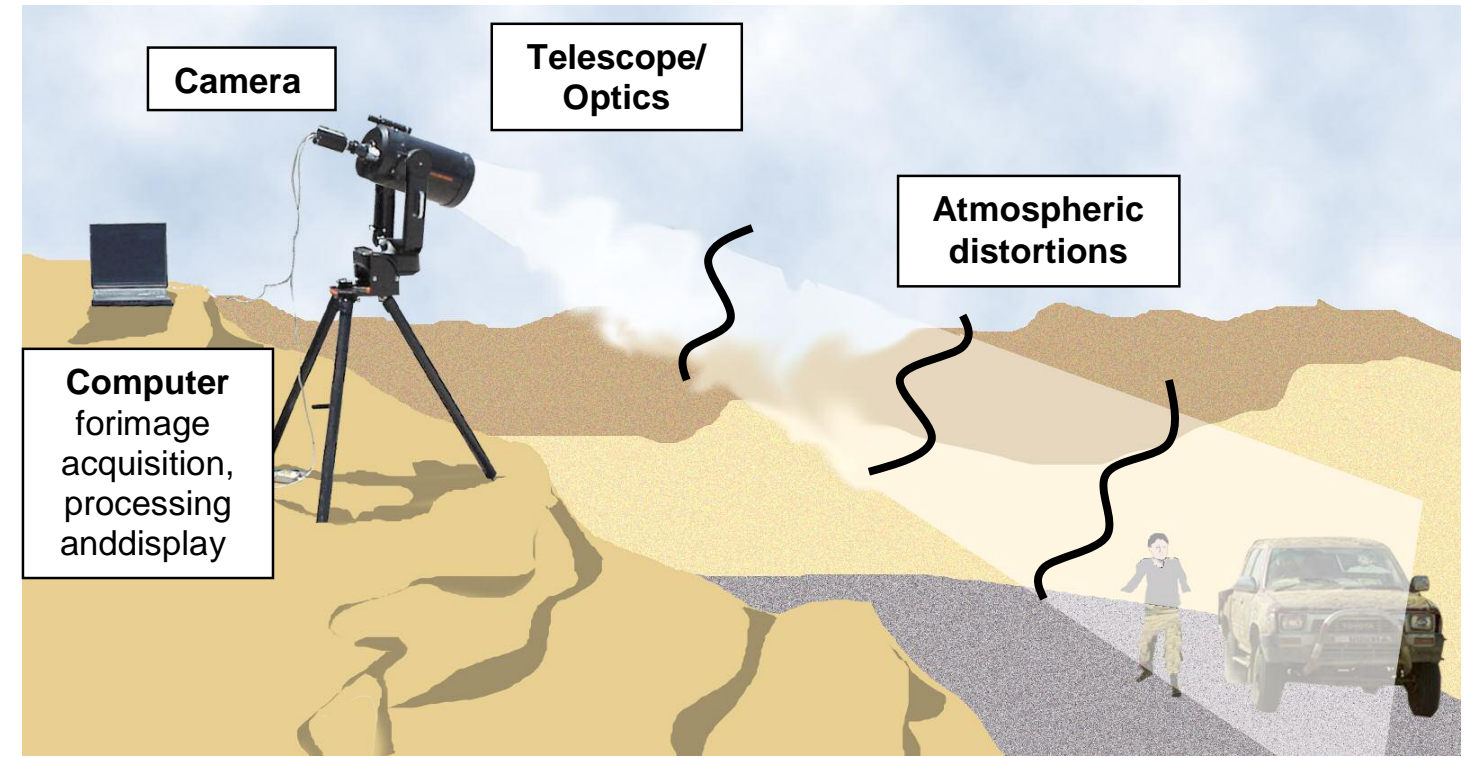

Figure 2. The critical components (telescope/telephoto optics, camera, and computer) of an enhanced video surveillance system are set up in a slant-path imaging geometry. 


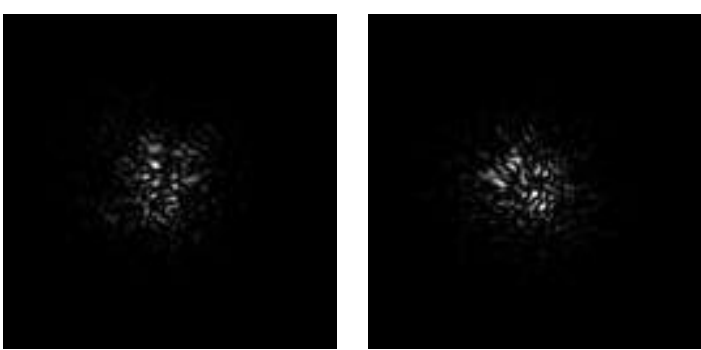

3a. Short exposures

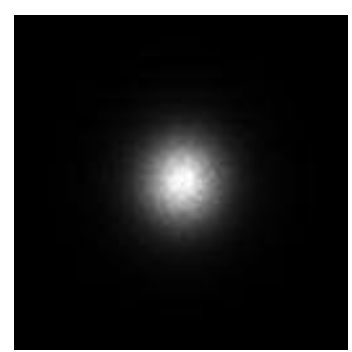

3b. Long exposure

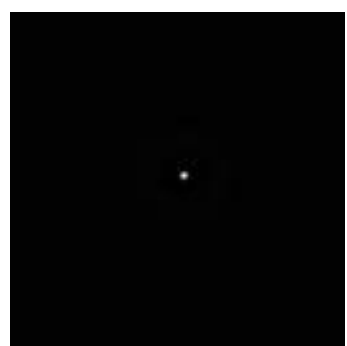

3c. Speckle processed

Figure 3. (a) Images of a point source taken through turbulence with an exposure short enough to freeze the atmosphere show many diffraction-limited speckles. (b) A long-exposure image demonstrates how the speckles average out, losing the high-resolution information. (c) The speckle-processed reconstruction from multiple short exposures results in a diffraction-limited image of the original point source.

\section{Design and operation}

The EVS system is designed to be portable and adaptable and can be customized to suit a customer's needs and desired application. In fact, the image-processing software could be integrated into most existing surveillance systems, adding significantly higher-resolution imaging capability to those systems. We implemented and tested two system configurations (Figure 4): The first system is configured for portability using a laptop with an IEEE 1394 (Firewire) chargecoupled device (CCD) camera for data acquisition and offline processing. The second system is configured for optimal speed using a video-rate, CCD camera and a four-processor computing platform for near-real-time, in-the-field image processing. Both configurations use the same Celestron 20-centimeter (8-inch) aperture telescope, although neither one requires this size telescope. In fact, the only requirement in terms of optics setup is that the lens assembly be of sufficient diameter and focal length to experience atmospheric aberrations. That is, the lens assembly should be at least a few inches or at least 6-8 centimeters in diameter with a meter or more in focal length. These requirements can be met easily not only with traditional telescopes but also with off-the-shelf spotting scopes or the more powerful telephoto lens assemblies. The CCD camera should have suitably sized pixels for adequate sampling, typically less than 10 microns for visible wavelengths. Such CCD cameras are commercially available from many vendors. 
The speckle-image-processing software application developed at LLNL controls the EVS system operation and can run on either Linux or Windows. The user interface of this software allows for full control of the camera parameters (e.g., exposure time and region-of-interest selection) as well as a real-time image update for target viewing, alignment, and focusing. To obtain multiple images at the full frame-rate requires only the push of a button, after which it is possible to view the images, save them, or use them in subsequent image processing. The final "product" - a high-resolution image-is also created with the push of a button. Figure 5 shows a screenshot of the software in use.

In general, the system is about as easy to use as any digital CCD camera with a computer interface. The essential information and instructions needed for creating the high-resolution imagery can be learned from a few pages of a user manual.

Please see Appendix D for a video description of the EVS system operation as well as highlights of field results.

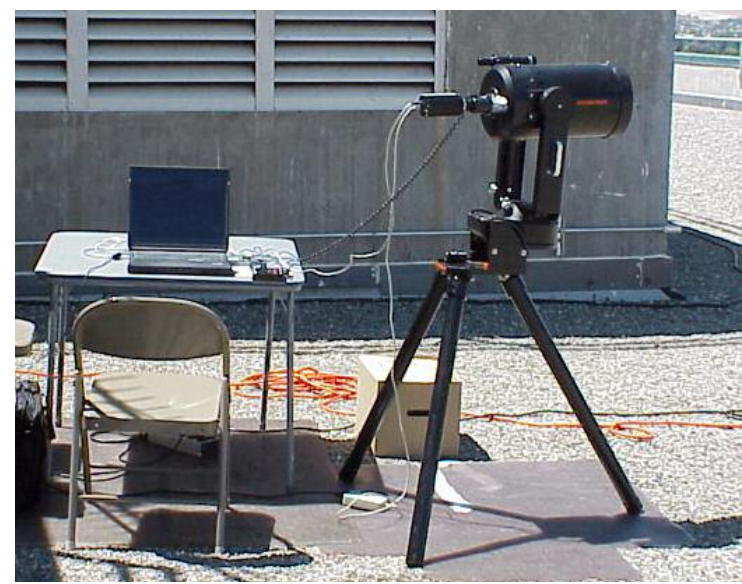

4a. Laptop EVS system

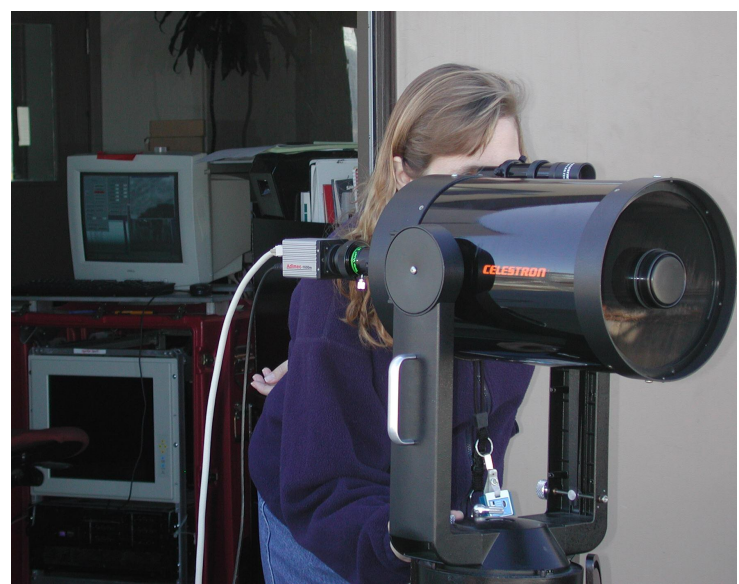

4b. Near real-time EVS system

Figure 4. Two Enhanced Video Surveillance (EVS) system configurations are tested. (a) One is a portable laptop EVS system set up on a rooftop. (b) The other EVS system is set up with a fourprocessor computing platform for near-real-time image processing. 


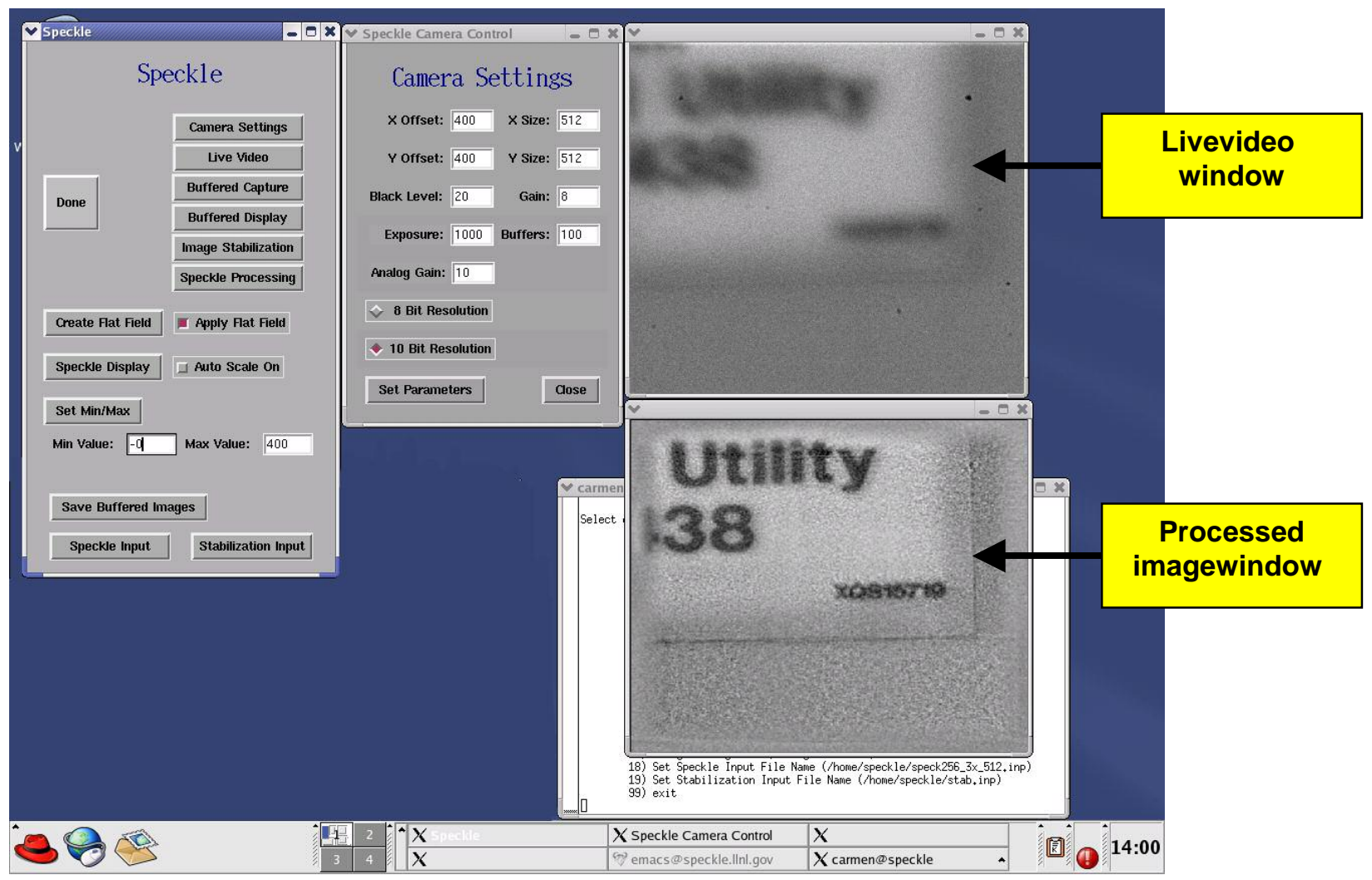

Figure 5. A screenshot of the LLNL-developed Enhanced Video Surveillance application software shows before and after images of a small sign viewed from about 100 meters away. The small letters in the center of the image are 2 millimeters tall.

\section{Field results}

We have demonstrated the EVS system's performance in a number of scenarios from shortrange imaging of personnel to long-range imaging of vehicles and buildings, as well as under varied illumination conditions from bright daylight to sunset to nighttime (with artificial illumination). Figure 6 shows personnel imaged at a range of 3.3 kilometers over a slight slantpath. The raw image shows significant atmospheric blurring, while the quality of the processed image is very near the theoretical limit of about one centimeter resolution. Note the clarity of the facial and hand features.

To demonstrate long-range imagery of vehicles, we took the EVS laptop system to the top of Mt. Diablo, a 1.8-kilometer peak located approximately 48 kilometers east of San Francisco. Figure 7(a) shows the view toward Livermore from the point of surveillance on Mt. Diablo. 
Figures 7(b) and (c) show long-range imagery of three vehicles acquired from 22 kilometers away before and after speckle processing. The processed image clearly shows three distinct types of vehicles. Note the flatbed truck is identifiable as a flatbed. Also, the fence posts along the road and between the fields are clearly visible.

For surveillance in low light, the EVS system can be outfitted with an image intensifier (or intensified camera). Using all the same equipment, but with an off-the-shelf, night-vision pocket scope inserted in front of the CCD camera, we demonstrated low light enhanced imaging. Before and after images of personnel and an automobile imaged from a 1.5-kilometer distance over a horizontal path at sunset are shown in Figure 8. The speckle-processed image gives greater detail in all aspects of the scene. Most notable is the clearly readable license plate.

For surveillance in very low light or complete darkness, some sort of artificial illumination is required (e.g., infrared illuminator). For the example shown in Figure 9, we placed a near-IR illuminator (830-nanometer center wavelength) a few meters in front of the personnel. As expected, the imagery is much noisier at lower light levels. Nonetheless, the speckle-processing algorithm performed very well, allowing facial and hand details to be observed at a kilometer away.

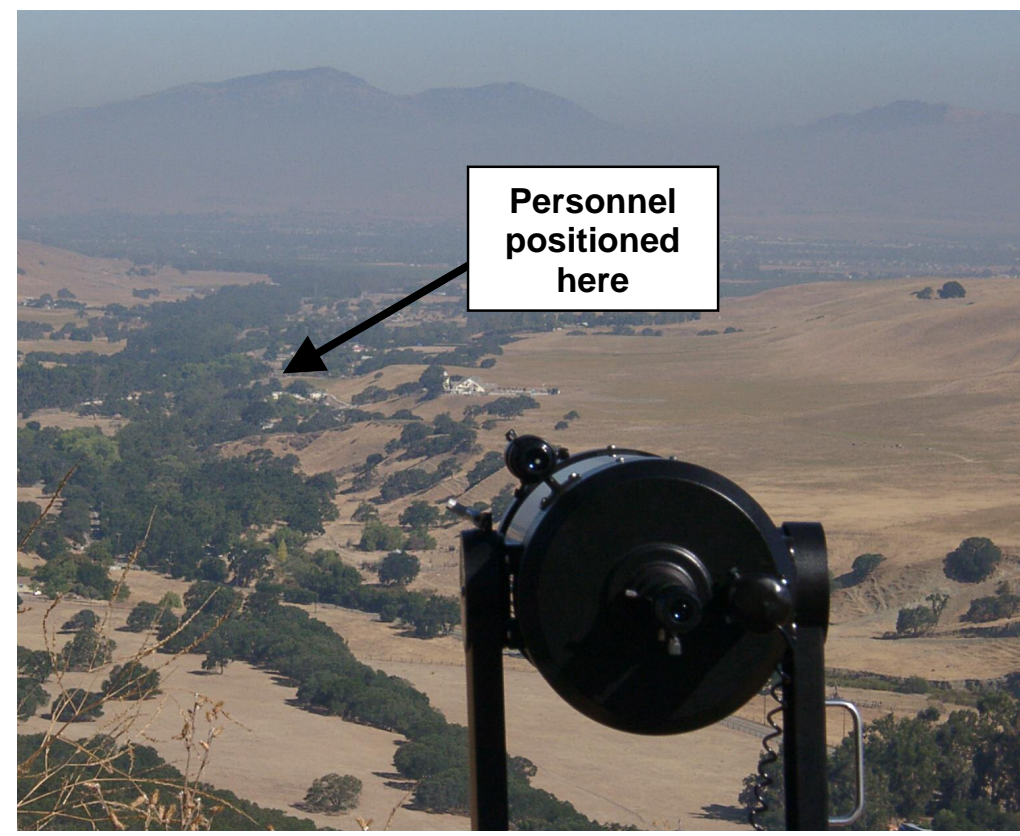

6a. View of target site from hillside 


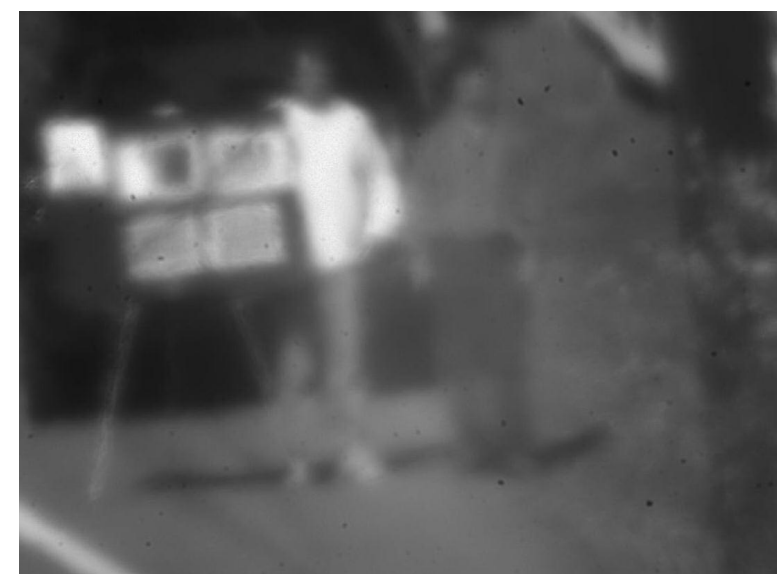

6b. Blurry, unprocessed raw image

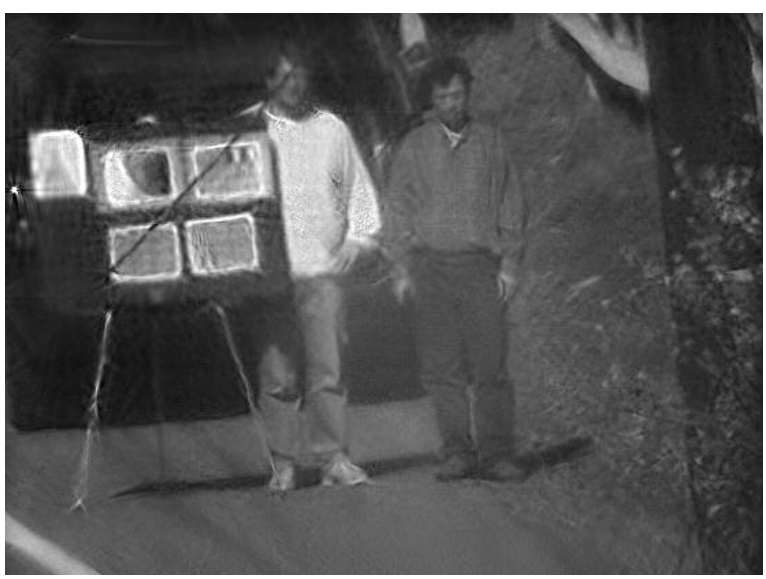

6c. Speckle-processed image

Figure 6. Personnel were imaged at a 3.3-kilometer (2-mile) distance through a Celestron 203millimeter (8-inch) aperture telescope with a monochrome CCD camera using a 15-millisecond exposure time. The speckle-processed image was produced using 100 raw frames.

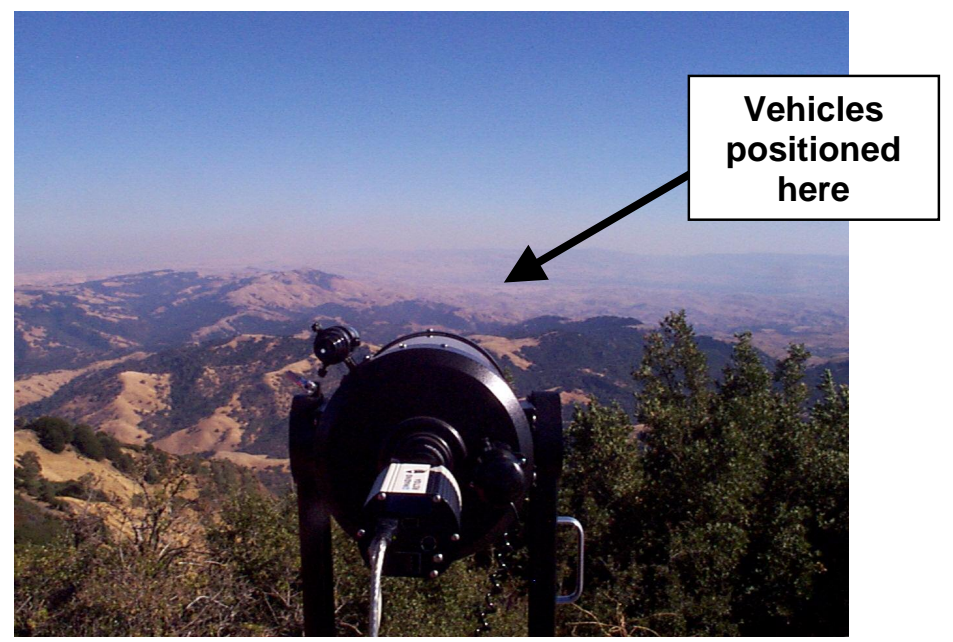

7a. View of target site from peak of Mt. Diablo

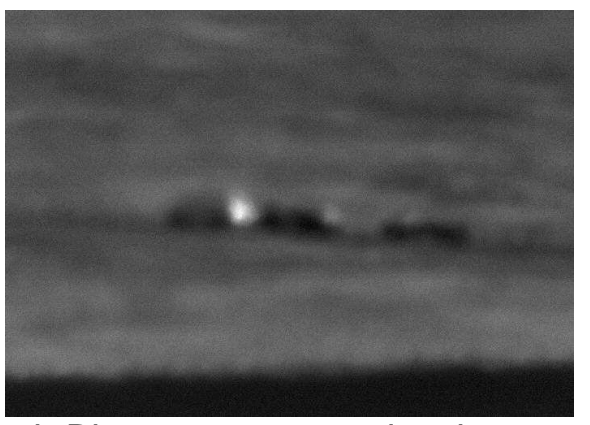

7b. Blurry, unprocessed raw image

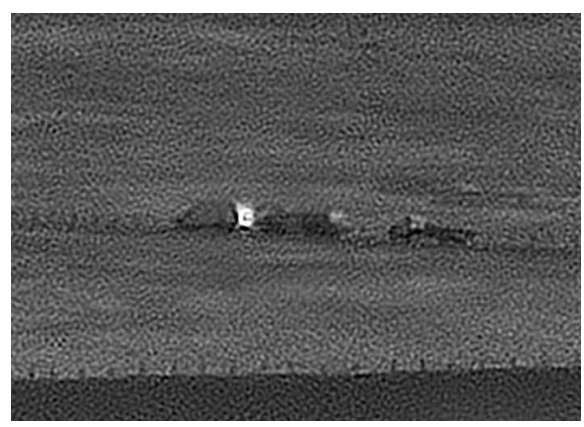

7c. Speckle-processed image

Figure 7. Vehicles imaged at a 22-kilometer (14-mile) distance through a Celestron 203-millimeter (8-inch) aperture telescope with a monochrome CCD camera using a 1-millisecond exposure time. The speckle-processed image was produced using 100 raw frames. 


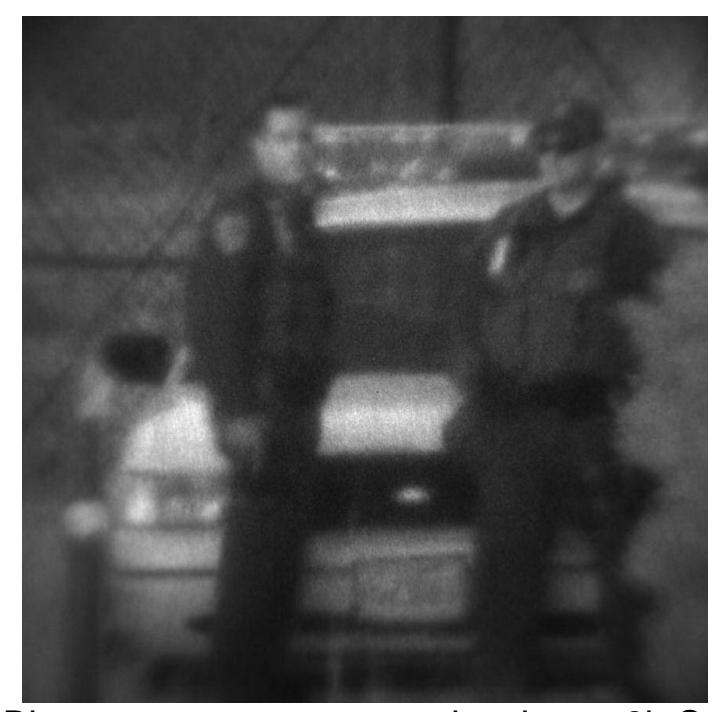

8a. Blurry, unprocessed raw image

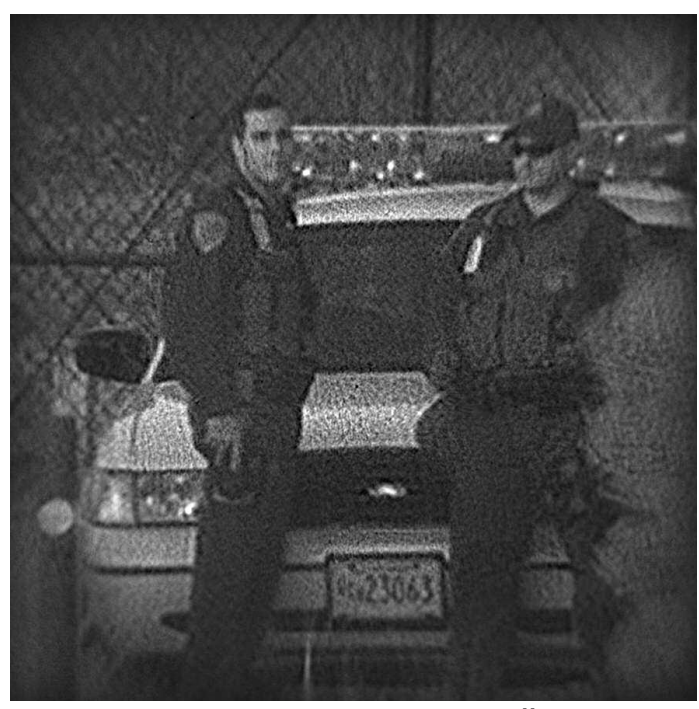

8b. Speckle-processed image

Figure 8. Personnel imaged at a 1.5-kilometer ( 1-mile) distance at sunset through a Celestron 203-millimeter (8-inch) aperture telescope with a monochrome CCD camera and image intensifier using a 10-millisecond exposure time. The speckle-processed image was produced using 100 raw frames.

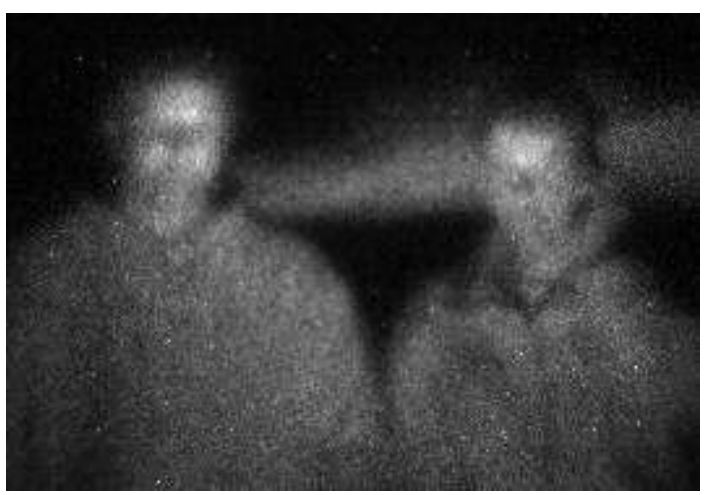

9a. Blurry, unprocessed raw image

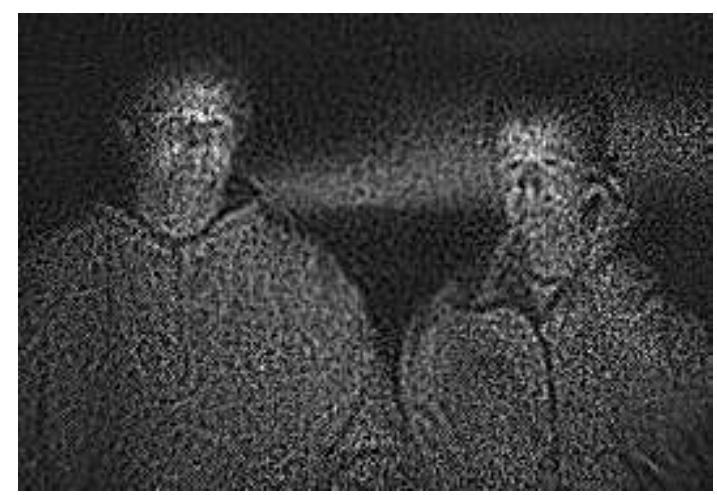

9b. Speckle-processed image

Figure 9. Personnel imaged at a 1.0-kilometer ( 0.63-mile) distance at night through a Celestron 203-millimeter (8-inch) aperture telescope with a monochrome CCD camera with image intensifier using an 8-millisecond exposure time and artificial illumination. The speckle-processed image was produced using 100 raw frames. 
10a. Product's competitors by manufacturer, brand name, and model number.

We were unable to identify any commercially available product that is in direct competition with LLNL's Enhanced Video Surveillance (EVS) with Speckle Imaging. However, listed below are the various representative products that can perform surveillance. EVS technology is complementary to many existing surveillance systems and potentially can be integrated into some of these systems rather than competing with them.

\begin{tabular}{|l|l|l|}
\hline \multicolumn{2}{|c|}{ Competitors } \\
\hline \multicolumn{1}{|c|}{ Manufacturer } & \multicolumn{1}{c|}{ Type } & \multicolumn{1}{c|}{ Model } \\
\hline Fujinon, Canon, or other & Image-stabilized binoculars & Several models \\
\hline JAI & Closed-circuit television systems & LOOKout 2000 \\
\hline Wescam & $\begin{array}{l}\text { Multisensor gyro-stabilized } \\
\text { imaging systems }\end{array}$ & MX-15 \\
\hline $\begin{array}{l}\text { Trex Enterprises, Adaptive } \\
\text { Optics Associates, or other }\end{array}$ & Custom adaptive optics systems & Several models \\
\hline
\end{tabular}


10b. Comparative matrix

\begin{tabular}{|c|c|c|c|c|c|c|}
\hline Feature & $\begin{array}{l}\text { Enhanced } \\
\text { video } \\
\text { surveillance } \\
\text { (EVS) system } \\
\text { with speckle } \\
\text { imaging }\end{array}$ & $\begin{array}{l}\text { Image- } \\
\text { stabilized } \\
\text { binoculars }\end{array}$ & $\begin{array}{l}\text { Closed- } \\
\text { circuit } \\
\text { televison } \\
\text { systems }\end{array}$ & $\begin{array}{l}\text { Multisensor } \\
\text { gyro- } \\
\text { stabilized } \\
\text { imaging } \\
\text { systems }\end{array}$ & $\begin{array}{l}\text { Custom } \\
\text { adaptive } \\
\text { optics } \\
\text { systems }\end{array}$ & $\begin{array}{l}\text { Competitive } \\
\text { advantage }\end{array}$ \\
\hline $\begin{array}{l}\text { Fixes blurring } \\
\text { due to } \\
\text { atmospheric } \\
\text { aberrations } \\
\text { beyond tip/tilt } \\
\text { (stabilization) }\end{array}$ & Yes & No & No & No & Partially & $\begin{array}{l}\text { Allows high- } \\
\text { resolution } \\
\text { imagery through } \\
\text { the horizontal or } \\
\text { slant path } \\
\text { atmospheric } \\
\text { turbulence }\end{array}$ \\
\hline $\begin{array}{l}\text { Corrects large/ } \\
\text { full field of view }\end{array}$ & Yes & No & No & No & $\begin{array}{l}\text { No, limited, } \\
\text { tunnel } \\
\text { vision }\end{array}$ & $\begin{array}{l}\text { Makes available } \\
\text { the full extent of } \\
\text { imagery at high- } \\
\text { resolution }\end{array}$ \\
\hline $\begin{array}{l}\text { A combination } \\
\text { of suitable } \\
\text { optics, camera } \\
\text { hardware, and } \\
\text { image } \\
\text { processing } \\
\text { software }\end{array}$ & Yes & No & No & No & No & $\begin{array}{l}\text { Enables } \\
\text { personnel } \\
\text { identification at a } \\
\text { few kilometers } \\
\text { and vehicle } \\
\text { identification at } \\
\text { tens of kilometers }\end{array}$ \\
\hline $\begin{array}{l}\text { Resolution } \\
\text { improvement } \\
\text { using the EVS } \\
\text { speckle-image- } \\
\text { processing } \\
\text { software }\end{array}$ & $\begin{array}{l}\text { Order of } \\
\text { magnitude or } \\
\text { more } \\
\text { (depends on } \\
\text { configuration } \\
\text { and } \\
\text { atmosphere) }\end{array}$ & None & None & None & $\begin{array}{l}\text { Potentially } \\
\text { some } \\
\text { improve- } \\
\text { ment in the } \\
\text { center of a } \\
\text { narrow field } \\
\text { of view }\end{array}$ & $\begin{array}{l}\text { This software is } \\
\text { currently } \\
\text { unavailable to } \\
\text { other types of } \\
\text { systems }\end{array}$ \\
\hline $\begin{array}{l}\text { Adaptable to } \\
\text { applications } \\
\text { other than } \\
\text { surveillance } \\
\text { (e.g., } \\
\text { ophthalmic } \\
\text { imaging, } \\
\text { astronomy) }\end{array}$ & Yes & No & No & No & Yes & $\begin{array}{l}\text { Easier to set up, } \\
\text { less expensive, } \\
\text { and less } \\
\text { cumbersome to } \\
\text { use than adaptive } \\
\text { optics systems } \\
\text { currently used in } \\
\text { astronomical and } \\
\text { ophthalmic } \\
\text { imaging systems. }\end{array}$ \\
\hline
\end{tabular}




\section{0c. Describe how your product improves upon competitive products or technologies.}

Many commercial surveillance systems fall under the category of closed-circuit television (CCTV) systems, which are intended for surveillance from a few meters away to a few tens of meters away because they use lower-resolution cameras with small lenses. Surveillance systems or devices intended for longer range do possess larger lenses, but typically use lower-resolution cameras and possess only the ability to provide image stabilization, which is used for removing jitter, wind shake, or platform motion, and not the higher-order atmospheric aberrations.

Adaptive optics systems for surveillance that correct higher-order atmospheric blurring have yet to reach the commercial sector, but if and when they do, they will likely suffer from tunnel vision and be difficult and cumbersome to set up and operate.

Enhanced Video Surveillance (EVS) with Speckle Imaging improves on all three of these types of systems. By modifying standard CCTV systems to use more suitable lenses and CCD cameras, it is possible to enable long-range, high-resolution CCTV imaging using the EVS imageprocessing algorithms. This same algorithm module could be integrated into suitably outfitted, existing long-range surveillance systems to provide significantly higher-resolution imagery. In the astronomical community, adaptive optics correction has been combined with speckle postprocessing to remove additional and uncorrected aberrations.

Although there is no established commercial market with competition for high-resolution surveillance imaging systems, commercialization could proceed down a couple of paths. One path is direct licensing of the image-processing software module to companies who want to integrate higher-resolution imaging into their current products. Alternatively, LLNL could partner with outside companies to develop totally new surveillance products that could then be commercialized. 


\section{1a. Describe the principal applications of this product.}

The principal application of Enhanced Video Surveillance (EVS) with Speckle Imaging is for performing high-resolution, long-range video surveillance. Applications for this type of surveillance capability are very broad and can serve a number of organizations, some of which are listed below:

Organizations:

- Law enforcement (e.g., police and FBI)

- Civilian or government security contractors and agencies

- Intelligence and Department of Defense agencies

- Private companies or large organizations (with valuable physical assets to protect)

- Wildlife researchers and magazines

Applications:

- Personnel monitoring and identification at a distance

- Vehicle monitoring, identification, and classification at a distance

- Remote-site monitoring

- License plate reading

- Perimeter monitoring of large facilities

- Border patrol

- Coastal monitoring of ships, ship-to-shore monitoring

- Airport security

- Wildlife observation and long-range photography

- Personal long-range photography 


\section{1b. List all other applications for which your product can now be used.}

The Enhanced Video Surveillance (EVS) with Speckle Imaging system is not limited to terrestrial surveillance applications. Because the basis for the image enhancement has its roots in astronomical imaging, an EVS system could easily be adapted to astronomical observations with a sufficiently large-aperture telescope. In addition, the modular design allows the software technology used in EVS to be integrated into imaging systems that look into the eye but at a much higher resolution. An example of such an imaging system is the Fundus camera, which is used in the diagnosis of retinal diseases, such as retinitis pigmentosa, glaucoma, diabetic retinopathy, and macular degeneration. Images obtained from current technology are limited in resolution because of aberrations in the eye itself, in particular the cornea and the lens. The EVS technology should enable high-resolution ophthalmic imaging because a portion of the aberrations in the eye is nonconstant as a result of eye motion, and non-constant aberrations are necessary for the imaging algorithm to function properly. This vision science application of EVS is now being researched at LLNL. 


\section{Summary}

Enhanced Video Surveillance (EVS) with Speckle Imaging solves the atmospheric blurring problem associated with imaging over medium to long distances (hundreds of meters to tens of kilometers) through horizontal or slant path turbulence. Although some surveillance systems possess large optics with high magnification, their ability to capture and display detail in the acquired image is fundamentally limited by atmospheric blurring. This problem requires a sophisticated image-processing approach that allows one to achieve the resolution potential of larger optics. Only then can increased resolution be obtained, allowing for target detection, recognition, or identification at much greater distances than is now possible. With the new ability to obtain substantially sharper images at longer distances, previously necessary close-up but unsafe observations can be made at further standoff distances.

Because of its modular and flexible design using readily available commercial off-the-shelf components, EVS technology can be commercialized as a stand-alone surveillance or observation system that is customized to suit various users and uses, or as an add-on to current surveillance products by companies seeking to provide higher-resolution images for their customers.

In summary, Enhanced Video Surveillance with Speckle Imaging can make our cities, nation, and world a safer and more secure place to live.

References:

1. D. T. Gavel, C. E. Max, E. J. Johansson, B. Sheerwood, M. Liu, B. Bradford, “Observations of Comet P/Shoemaker-Levy 9 Impact on Jupiter from Lick Observatory Using a High Resolution Speckle Imaging Camera," IAU Symposium 156, Space Telescope Science Institute, Baltimore, MD, May 912, 1995.

2. T. W. Lawrence, D. M. Goodman, E. M. Johansson, and J.P. Fitch, "Speckle imaging of satellites at the U.S. Air Force Maui Optical Station," Applied Optics 31, No. 29, 6307-6321 (1992).

3. C. J. Carrano, "Speckle imaging over horizontal paths," Proceedings of the SPIE - High Resolution Wavefront Control: Methods, Devices, and Applications IV, 4825 (2002).

4. C. J. Carrano, "Anisoplanatic performance of horizontal-path speckle imaging," Proceedings of the SPIE - Advanced Wavefront Control: Methods, Devices, and Applications, 5162 (2003). 
13. Contact person to handle all arrangements on exhibits, banquet, and publicity.

Name:

Position:

Organization:

Address:

City:

State:

Zip Code:

Country:

Phone:

Fax:

E-mail:
Lisa A. Chartrand

Partnering Services Administrator

Lawrence Livermore National Laboratory

7000 East Avenue, L-795

P.O. Box 808

Livermore

California

94550

USA

(925) 422-2297

(925) 423-8988

chartrand1@|lnl.gov 


\section{Appendix A - Letters of Support}




\section{Appendix B - Newspaper clipping}

From the Sunday, February 3, 2002 edition of the Valley Times newspaper 


\section{Appendix C: Selected Publications}




\section{Appendix D: Video Description}

